\title{
Para recordar a Ángel J. Cappelletti
}

Josu Landa

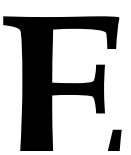

n noviembre de 1994, falleció el eminente historiador de la filosofía argentino, Ángel J. Cappelletti. Unos dos meses antes había impartido un excelente curso sobre filosofía de la Edad Media, dentro del pro-

\ grama de la Cátedra Extraordinaria "Maestros del Exilio Español". A decir verdad, Cappelletti no era una celebridad en nuestro medio filosófico. Sin embargo, su riguroso y prolífico trabajo de exégesis de los principales textos que integran las tradiciones filosóficas griega y medieval han gozado siempre del reconocimiento de los colegas interesados en el tema; y en los lugares donde pudo influir más (Argentina, Uruguay y, sobre todo, Venezuela), Cappelletti llegó a ser un elemento central de la comunidad filosófica del caso.

Aunque fue un gran viajero, Cappelletti sólo estuvo en México, durante lapsos muy breves, en tres ocasiones. La primera tuvo lugar en los ya remotos tiempos en que Joaquín Sánchez Macgrégor ejercía la docencia en la Universidad de Puebla y tuvo a bien invitarlo a dar un curso en esa institución. Ese viaje propició sus nexos con los filósofos mexicanos. En concreto, hizo posible que entablara con Fernando Salmerón una prolongada amistad, cimentada en la mutua afición por el trabajo filosófico serio. En 1988, tuvo lugar un segundo viaje. Fue cuando entró en contacto con Juliana González y con los jóvenes filósofos mexicanos más interesados en la filosofía griega. Fue también cuando estableció sólidos nexos con un grupo de investigadores del Instituto de Investigaciones Filológicas, entre los que destacan Mauricio Beuchot y Roberto Heredia. La tercera visita del gran exégeta y maestro de filosofía que fue Cappelletti se concretó en 1995, con motivo del ya citado curso sobre filosofía medieval.

Hay muchas formas de rendir homenaje a quien ha hecho tan importantes contribuciones a la cultura filosófica en nuestro medio. Una de ellas consiste en incentivar la lectura de su obra, mostrando las bases teóricas y metódicas que la sustentan. He optado por este recurso, porque nunca es tarde para echar mano de un fruto cosechado con antelación, cuando el fruto es realmente sustancioso 
y duradero. En su segundo viaje a México, hace ocho años, Cappelletti tuvo la deferencia de concederme una entrevista, en la que - entre otras cosas-explicó los supuestos centrales de su trabajo hermenéutico. Dado que la transcripción de dicha conversación apareció en una revista cultural venezolana de vida exigua y circulación bastante limitada, ${ }^{*}$ no estará de más reproducir un fragmento de la misma. Se trata de un modestísimo acto de des-cubrimiento de un autor, que merece ser mejor conocido por la comunidad filosófica de México.

\section{Entrevista (fragmento)}

\section{¿Podría sintetizar su teoría de la historia de la filosofía?}

Yo concibo la historia de la filosofía como una parte de la historia de la cultura. No acepto, de ninguna manera, la concepción de una historia que se mueve dentro de su propio ámbito, con exclusión de la sociedad y de las otras manifestaciones de la cultura. Una historia "interna", que atiende exclusivamente al desarrollo lógico de las ideas, es una historia abstracta, por consiguiente, falsa. La historia de la filosofía se vincula, antes que nada, como toda manifestación de la cultura, con la historia de la sociedad, con la historia de las formas políticas y, desde luego, con la historia de las demás formas culturales: la religión, el arte, la literatura; a tal punto que a veces es inseparable de ellas. Sobre todo, si nos referimos a periodos como la Grecia clásica o el del Medioevo -que son los campos en que he trabajado- desvincular, por ejemplo, la filosofía antigua del pensamiento social o político, o desvincular la filosofía medieval de la historia de la religión y de la tecnología sería una abstracción completamente inútil, vacua.

Si fuera dable asignarle un nombre a esta concepción de la historia de la filosofía, ¿cuál sería para usted el más apropiado?

Se trata de una concepción sociocultural de la historia de la filosofía. No se trata de una concepción linealista, en la cual se tenga en cuenta un solo factor, por ejemplo, la lucha de clases; porque la lucha de clases es un factor importante, pero no se puede hacer la historia en función de tal factor exclusivamente. Digo esto porque, desde luego, hay quienes tienen esta postura; lo cual lleva a esquematizar y empobrecer, y en definitiva a no comprender la historia de la

* Se trata de la revista Escarabajo, núm. 5, El Tigre (Venezuela), Consejo Nacional de Cultura-Ateneo de El Tigre, julio de 1989. 
filosofía.

Usted acaba de hacer referencia a un tipo de reduccionismo. Sin embargo, este que tiene que ver con la lucha de clases no sería el único.

¡Claro! Desde luego que hay otras concepciones que son sumamente parciales. Una de ellas es la que aludía al principio, la concepción logística, según la cual lo único que interesa es el desarrollo interno de las ideas, la generación de las ideas a partir de otras, con prescindencia del contexto social. Este quizá sea el reduccionismo más grave de todos, porque aísla a la filosofía, al pensar filosófico, del mundo histórico, del mundo humano.

Usted trata de fundar una teoría del tránsito de la magia y la mitología a la filosofía...

La filosofía nace en Grecia vinculada estrechamente a concepciones e intuiciones que son de origen evidentemente prefilosófico. Esta concepción del mundo, este conjunto de intuiciones de las cuales parte la filosofía y sobre las cuales elabora su teoría racional, pertenece a una etapa del pensamiento que podríamos llamar, más que religiosa, mágica. Entiendo por "magia" una concepción del mundo en la cual no se han opuesto todavía Dios y mundo, cuerpo y alma; ni tampoco admite, concomitantemente, en el terreno práctico, la oposición tuyo-mío (o sea, la idea de la propiedad privada) y la oposición entre gobernante y gobernado (es decir, la idea del Estado). En esta concepción primitiva del mundo, que es también una concepción de la sociedad y de la vida humana, que llamamos "magia", tiene su punto de partida la filosofía, en Grecia. Quiero aclarar que la magia no es, desde luego, una cosmovisión formalmente expuesta en ningún texto, porque estamos hablando de épocas prehistóricas, por consiguiente, anteriores a todo documento escrito. Más aún, hay que aclarar que la magia es una concepción del mundo que se funda en una serie de ritos y ceremonias, es decir, que se funda en una praxis. De esa praxis se infiere dicha concepción del mundo. Pero la magia no es primariamente algo teórico, sino una práctica, por la cual el hombre se vincula con la totalidad de la naturaleza, como parte de ella. De esta serie de ceremonias de tipo mágico, como podría ser la celebración del advenimiento de la primavera, la resurrección de la vegetación, etcétera, que implican a veces ritos sangrientos, en los cuales se sacrifica un toro, por ejemplo, un animal que simboliza la fecundidad rústica..., de esa serie de ritos se puede inferir, con claridad, esta concepción mágica. Dicha concepción está centrada en la idea de Naturaleza, de physis. Como por obra de un poder omnipresente, que vincula entre sí a todos los seres vivientes y no vivientes (plantas, animales, hombres, montañas, ríos, piedras...), todo 
está, digamos, como penetrado por ese principio que es la Naturaleza; y todos los seres vivientes, por consiguiente, son hermanos entre sí, participan de una misma naturaleza, tienen la misma sangre. Así como los miembros de una misma tribu, de un clan primitivo, se consideraban entre sí descendientes de un único antepasado, así en la concepción mágica, todos los seres vivientes, no solamente los hombres, se consideran hijos o miembros de una única fuerza universal, que en Grecia se llama physis, en la India se llama Brahman, en China se llama Tao, entre los melanesios y polinesios se llama Manas, y así sucesivamente.

¿Cuál es el proceso que realizan los primeros filósofos griegos, a partir de ese concepto mágico primigenio ("physis")?

El punto de partida es una intuición, que Nietzsche llama "metafísico-mística", y que quizá con mayor propiedad deberíamos llamar "metafísico-mágica". A partir de esta intuición originaria, se constituye la filosofía como un saber que se funda en la experiencia y en la dialéctica, o sea, en el raciocinio; pero siempre partiendo de una intuición que no puede ser de por sí fruto de la experiencia ni de la pura abstracción, porque evidentemente el conocimiento y la experiencia de los hombres de aquella época no se extendía hasta tal nivel de abstracción. La intuición de la physis es anterior a todo raciocinio; más bien condiciona el raciocinio y la experiencia.

¿Lo que usted acaba de decir significa que los primeros filósofos griegos transitan una vía opuesta a la inducción: que ejecutan un proceso distinto al de una síntesis de percepciones empíricas diversas?

Hay inducción y hay deducción; pero a partir de una intuición que está dada no por una inducción previa. Es decir, el error sería pensar, como pensaron muchos historiadores de la época del positivismo y de principios de este siglo, que la filosofía empieza desde cero a inducir; esto es, se empieza a observar fenómenos, se unen entre sí, se generaliza... Esta sería una visión enteramente anacrónica, puesto que no corresponde a esa época del pensamiento humano.

Usted se ha visto en la necesidad de demoler algunos "idolos", de denegar algunas creencias sólidamente asentadas en ciertas historias de la filosofía. Por ejemplo, sobre Heráclito...

Heráclito no es, como corrientemente suele decirse, un filósofo del devenir, sino ante todo un filósofo del ser. En este sentido, Heráclito está al lado de Parménides, no en frente. Hay diferencias y oposición entre ambos, pero no en cuanto a que Heráclito es un filósofo del puro devenir y Parménides un filósofo 
del puro ser. Ambos son filósofos del ser. Lo que pasa es que se trata de dos concepciones diferentes del ser. Ambos son monistas, pero en Parménides hay un monismo estático, que excluye el movimiento y reduce toda pluralidad cósmica a una mera apariencia; mientras que en Heráclito la afirmación de la unidad del ser no implica la negación de la pluralidad, sino una concepción de ésta como modalidades de unidad. Entonces, la concepción según la cual se considera a Heráclito como un filósofo del devenir, como un filósofo que sólo admite la existencia de fenómenos, de acontecimientos puntuales, sin ninguna sustancia que le sirva de fundamento, es una concepción basada en una interpretación muy parcial que atiende sólo a un grupo de fragmentos heraclíteos. Esta interpretación, que tiene solamente en cuenta los fragmentos del río y no tiene en cuenta los fragmentos del logos y de la unidad, se corresponde en realidad no con el pensamiento de Heráclito, sino de algunos pseudo-heraclíteos (como Cratilo); filósofos que estaban ya al borde del escepticismo. Heráclito de ninguna manera es un escéptico. Era un metafísico monista, que afirmaba la unidad del ser a través de la pluralidad de los fenómenos. 